\title{
STATISTICAL AND REGRESSION ANALYSIS OF VibRation OF CARBON STEEL CUTTING TOOL FOR TURNING OF EN24 STEEL USING DESIGN OF EXPERIMENTS
}

\author{
Amit Aherwar $^{1^{*}}$, Deepak Unune ${ }^{2}$, BhargavPathri $^{3}$, Jai kishan ${ }^{4}$ \\ ${ }^{1,2,3,4}$ Department of Mechanical Engineering, Malaviya National Institute of Technology, \\ Jaipur-302017, India
}

\begin{abstract}
Machining is a convoluted process in which many variables can deleterious the desired results. Among them, cutting tool vibration is the most decisive phenomenon which influences dimensional precision of the components machined, functional behavior of the machine tools and life of the cutting tool. In a machining operation, cutting speed, depth of cut and the tool feed rate principally influence cutting tool vibrations. In this paper, effects of cutting speed, feed rate and depth of cut on cutting tool vibration in both the directions, i.e. axial and tangential are investigated by the statistical methods of signal to noise ratio $(S N R)$, analysis of variance (ANOVA) and regression analysis. Experiments have been conducted using the $L_{9}$ orthogonal array in the centre lathe machine. Carbon steel was selected as cutting tool materials to conduct the experiments. From experimental results, the amplitude of vibration of the cutting tool was ascertaining for each machining performance criteria. The significance and percentage contribution of each parameter were determined by Analysis of variance (ANOVA).It has been observed that cutting speed has a maximum contribution on cutting tool vibration in both the directions. Variation of the vibration of cutting tool with machining parameters was mathematically modeled by using the regression analysis method. The predicted value from the developed model and experimental values are found to be very close to each other justifying the significance of the model. Confirmation runs demonstrates that the optimized result and the values obtained through regression analysis are within the prescribed limit
\end{abstract}

KEYWORDS: ANOVA, Tool Vibration, Taguchi method, DOE, Centre Lathe

\section{INTRODUCTION}

Metal cutting is one of the imperative and extensively used manufacturing processes in engineering industries. It primarily focuses on the tool's features, input materials of work piece, and machine parameter settings influencing process efficiency and output characteristics. A significant expansion in process efficiency may be acquired by the optimization of process parameter that identifies and find out the regions of critical process control factors leading to desired output or responses to tolerable variations ensuring a lower cost of manufacturing [1]. Cutting conditions include cutting speed, cutting fluids, depth of cut and feed. For a machining process such as turning, vibration is a common problem, which affects the machining performance particularly, the surface finish and tool life. Dynamic motion between the cutting tool and the work piece results in severe vibrations in the machining process. The monitoring of 
manufacturing processes and the conditions of equipment are the crucial part of a critical tactic that impels manufacturing industries towards being leaner and more vying [1,3]. Many sensors were reported for tool condition monitoring system, namely; power sensors, vibration sensors, vision sensors, temperature sensors, touch sensors, force sensors, acoustic emission sensors, flow sensors and so on $[4,2,5]$.The role of sensors and their signal interpretation capability is critical in any automation process. The processing and investigation of signals is significant because it will improve production capacity, reliability, reduced downtime and enhanced machining quality [6]. Byrne et al. [7] described that $46 \%$ of the sensors monitoring systems were fully functional, $16 \%$ had limited functionality, $25 \%$ were non-functional owing to technical limitations and $13 \%$ were switched over to alternate systems. Sensors based systems are the most vital choice for prediction the condition of cutting tool.

Rotary and/or reciprocating parts in machines impose different vibration amplitudes. Machine tools are likely to deteriorate in their performance with respect to time due to various aspects such as ageing, unbalance, wear and tear, looseness of parts etc., and resulting in an increase overall vibration level. Uncontrolled machine tool vibrations can adversely affect the dimensional accuracy, tool life and surface finish. Increased vibration level could account about $70 \%$ of the failures in the machine tools. Lathe is one of the most critical machine tool in manufacturing industries. The quality of the workpiece hinge essentially on the condition of the lathe. It is difficult to exploit the optimum functions of a machine owing to numerous adjustable machining parameters [8]. The Taguchi's dynamic experiments are efficient and systematic method to find out the optimum settings of machining parameters [9-11]. The analysis of variance (ANOVA) is extensively used to study the effects of factors on responses. In experimental studies, ANOVA is often employed prior to other statistical analysis. Afterwards that, regression analysis is widely applied to show a relation between independent variables and dependent variables [8].

The literature review shows that no plausible studies have been performed to examine the vibration of the cutting tool in axial and tangential direction respectively with turning of EN24 steel. The main purpose of this paper is to monitor the vibration level of cutting tool and investigate the effects of machining parameters on the cutting tool i.e. carbon-steel. It is presumed that the condition of the machine and its components is good in all aspects such as machine foundation, rigidity of the machine components. The vibration analysis is conducted through collecting the overall vibration amplitude (RMS) and plotting the vibration data. From the basic principle and characteristic feature of the centre lathe process, it has been discovered that the machining parameters, such as depth of cut, cutting speed and feed rate are the important controllable process parameters and therefore selected for the investigation. Taguchi's $\mathrm{L}_{9}$ orthogonal array was used to analyze the experiment process [12].Furthermore, analysis of variance is used to investigate the statistical significance of the cutting parameters. Finally, confirmation test was carried out using the optimal conditions of cutting which were resulted via Taguchi method.

\section{MATERIAL AND METHOD}

In this study, EN 24 steel was used as a workpiece. The chemical composition of the workpiece sized $\varnothing 25 \times 75 \mathrm{~mm}$ is given in Table 1 . The experimental studies were carried out on a Mori Seiki NL 2500 centre Lathe under dry cutting conditions. Carbon steel was used as the cutting tool material. The vibrometer placed in two different locations to measure axial and tangential, vibrations respectively. The experiments were repeated for different speed, depth of cut and feed rate. Readings were noted down in three different levels, i.e. three different cutting speeds, depth 
of cut, and feed rate. In this study, cutting speed (CS), depth of cut (DOC) and feed rate (FR) selected as control factors and their levels are as shown in Table 2. The selection of an appropriate orthogonal array is the first step of the Taguchi method. The most appropriate orthogonal array $\left(\mathrm{L}_{9}\right)$ was selected to study the effects of machining parameters and the optimal machining conditions [13]. The nine possible combinations of machining parameters (shown in Table 3) were formed to analyze their effect on cutting tool vibrations. The next section discusses experimental design and analysis method used in this research work.

Table 1 Chemical composition of the work piece

\begin{tabular}{llllllll}
\hline $\mathrm{C}$ & $\mathrm{Si}$ & $\mathrm{Mn}$ & $\mathrm{S}$ & $\mathrm{P}$ & $\mathrm{Cr}$ & $\mathrm{Mo}$ & $\mathrm{Ni}$ \\
\hline $0.36-$ & $0.10-$ & $0.45-$ & $0.040 \%$ & $0.035 \%$ & $1.0-1.4 \%$ & $0.2-$ & $1.3-1.7 \%$ \\
$0.44 \%$ & $0.35 \%$ & $0.70 \%$ & & & & $0.35 \%$ & \\
\hline
\end{tabular}

\section{EXPERIMENTAL DESIGN}

Design of experiment is an imposing statistical technique for investigating the unknown attributes of the machining parameters in the experimental process and for studying and modeling the interaction between the factors [14]. The classical experimental design methods are overly complex and not easy to apply. Additionally, when the number of machining parameters increases a large number of experiments are required [15]. Therefore, the factors instigating variations should be determined and checked under laboratory environments. These studies are counted below the scope of off-line improvement of quality [16]. The Taguchi method usually used to reduce the number of experiments by using orthogonal arrays and also attempts to minimize the effects of control factors. The basic idea of the Taguchi method is to make sure quality in the design phase. The greatest benefits of the Taguchi method are to cut the experimental time and reduce costs [17].

The Taguchi technique is typically used for parametric design of product or process design that focus on determining the parameter settings producing the best levels of a quality characteristic (performance measure) with minimum variation. Selection of control factors is a very critical stage in the design of experiments. More factors should be investigated in order to identify nonsignificant variables at the initial prospect $[18,20]$. Taguchi produces a typical orthogonal array to accommodate this requirement. $\mathrm{S} / \mathrm{N}$ ratio compares the level of a desired signal to the level of background noise. If the ratio is high, the background noise is less obtrusive. It is used casually to refer to the ratio of useful information to false or immaterial data in a conversation or exchange. In other words, the standard deviation cannot be lessened first and the mean carried to the target $[18,19,20]$.Taguchi empirically founded that the two stage optimization procedure involving S/N ratios indeed gives the parameter level combination, where the standard deviation is minimum while keeping the mean on target [21].This suggests that engineering systems act in such a manner that the manipulated production factors can be separated into three categories: i.e. control factors, signal factors and factors. Process variability influenced by control factors measured in terms of the $\mathrm{S} / \mathrm{N}$ ratio. In general, the $\mathrm{S} / \mathrm{N}$ ratio characteristics can be divided into three classes: "larger-the-better", "smaller-the-better" and "nominal-the-best". Further, ANOVA is typically used to find out the statistical significance of the cutting parameters. The optimum combination of the cutting parameters is determined by the aid of ANOVA and S/N ratios. Finally, confirmation experiments are done using the optimum machining parameters which were found 
with the help of Taguchi optimization method and thereby validation of the optimization is tested [22].

The experimental design for three turning parameters (cutting speed, feed rate and depth of cut) with three levels are organized by the Taguchi's $\mathrm{L}_{9}$ orthogonal array as shown in Table 3 . In the Taguchi method, the orthogonal array can provide an efficient means to perform the experiments with the least number of trials. Taguchi used as the quality characteristic of choice on the basis of signal-to-noise $(\mathrm{S} / \mathrm{N})$ ratio. The-smaller-the-better performance characteristic for tool vibration were applied in order to obtain the optimal cutting parameters. $\mathrm{S} / \mathrm{N}$ ratio is defined as follows:

$S / N(\eta)=-10 \log \left[\frac{1}{n} \sum_{i=1}^{n} y_{i}^{2}\right]$

Where $y_{i}$ is the observed data of the experiment and $n$ is the number of experiments. The $\mathrm{S} / \mathrm{N}$ ratios of three factors using Eq. (1) were calculated for amplitude of tool vibrations. Moreover, ANOVA was applied with $95 \%$ confidence level to determine the most significance level of the variables on tool vibrations. Optimization process based on the Taguchi method was performed by Minitab software evaluation version. Minitab is powerful software that helps to solves many statistical problems with ease and is frequently used in performing statistical analysis and quality improvement in the field of statistics and engineering. In the next session, analysis of signal to noise ratio of cutting parameters in both axial and tangential directions is explained. Further, analysis of variance is discussed to determine most significant parameter which influences cutting tool vibration. Finally, confirmation runs have been carried out to verify the optimized result and the values obtained from regression equations.

Table 2 Cutting parameters and their levels

\begin{tabular}{llllll}
\hline Variables & $\begin{array}{l}\text { Variables } \\
\text { designation }\end{array}$ & Level 1 & Level 2 & Level 3 & Units \\
& & & & & \\
\hline Cutting speed & A & 100 & 150 & 200 & RPM \\
Depth of cut & B & 0.5 & 0.75 & 1.0 & $\mathrm{~mm}$ \\
Feed rate & $\mathrm{C}$ & 0.1 & 0.2 & 0.3 & $\mathrm{~mm} / \mathrm{rev}$ \\
\hline
\end{tabular}

Table 3 The analysis layout using $\mathrm{L}_{9}$ orthogonal array

\begin{tabular}{cccc}
\hline Trial no. $\mathrm{L}_{9}$ & A & B & C \\
\hline 1 & 1 & 1 & 1 \\
2 & 1 & 2 & 2 \\
3 & 1 & 3 & 3 \\
4 & 2 & 1 & 2 \\
5 & 2 & 2 & 3 \\
6 & 2 & 3 & 1 \\
7 & 3 & 1 & 3 \\
8 & 3 & 2 & 1 \\
9 & 3 & 3 & 2 \\
\hline
\end{tabular}




\section{EXPERIMENTAL RESULTS AND DISCUSSION}

\subsection{Analysis of the signal-to-noise (S/N) Ratio}

The Taguchi method employs $\mathrm{S} / \mathrm{N}$ ratio to determine the mutations of the experimental design. The equation of "smaller-the-better" (Eq. 1) was selected for the calculation of S/N ratio since the lowest values of cutting tool vibration level was the desired results in terms of more dependable product quality. $\mathrm{S} / \mathrm{N}$ ratios of cutting tool vibration in axial and tangential direction are presented in Table 4. The mean amplitude of cutting tool vibrations, occurred during machining of the EN 24 steel was measured later on the experiments performed according to the $\mathrm{L}_{9}$ orthogonal array. The experimental results and $\mathrm{S} / \mathrm{N}$ ratios calculated according to 'the-smallerthe-better' quality characteristic were given in Table 4.

Table 4 Experiment result for cutting tool vibration and $\mathrm{S} / \mathrm{N}$ ratio

\begin{tabular}{llllllll}
\hline $\begin{array}{l}\text { Analysis } \\
\text { Run }\end{array}$ & A & B & C & $\begin{array}{l}\text { RMS of } \\
\text { vibration in } \\
\text { Axial } \\
(\mathrm{mm} / \mathrm{min})\end{array}$ & $\begin{array}{l}\text { S/N ratio } \\
\text { in Axial } \\
(\mathrm{db})\end{array}$ & $\begin{array}{l}\text { RMS of } \\
\text { vibration } \\
\text { in } \\
\text { Tangential } \\
(\mathrm{mm} / \mathrm{min})\end{array}$ & $\begin{array}{l}\text { S/N ratio in } \\
\text { Tangential } \\
(\mathrm{db})\end{array}$ \\
\hline 1 & 1 & 1 & 1 & 0.89 & 1.0122 & 1.04 & -0.3406 \\
2 & 1 & 2 & 2 & 1.08 & -0.66848 & 2.14 & -6.6082 \\
3 & 1 & 3 & 3 & 1.22 & -1.7272 & 3.22 & -10.1571 \\
4 & 2 & 1 & 2 & 2.44 & -7.7478 & 3.14 & -9.9385 \\
5 & 2 & 2 & 3 & 3.82 & -11.6413 & 4.71 & -13.4604 \\
6 & 2 & 3 & 1 & 3.53 & -10.9555 & 4.93 & -13.8569 \\
7 & 3 & 1 & 3 & 4.88 & -13.7684 & 5.87 & -15.3727 \\
8 & 3 & 2 & 1 & 4.83 & -13.6789 & 5.72 & -15.1479 \\
9 & 3 & 3 & 2 & 5.92 & -15.4464 & 6.93 & -16.8146 \\
\hline
\end{tabular}

\subsubsection{For axial direction}

In Taguchi method the most essential criterion for analyzing experimental data is signal-to-noise ratio. According to this method, the $\mathrm{S} / \mathrm{N}$ ratio should have a maximum value to obtain optimum cutting conditions. Thus, the optimum cutting condition was found as $1.0122 \mathrm{~S} / \mathrm{N}$ ratios for RMS of vibration in $\mathrm{L}_{9}$ orthogonal array in table 4 . The optimum cutting conditions, which were the cutting speed of $100 \mathrm{~m} / \mathrm{min}$, the depth of cut of $0.5 \mathrm{~mm}$, and the feed rate of $0.1 \mathrm{~mm} / \mathrm{rev}\left(\begin{array}{lll}1 & 1 & 1\end{array}\right.$ orthogonal array) were obtained for the best RMS of vibration values. According to the Taguchi design, the level values of the factors obtained for RMS of vibration and their interpretations may be made according to the level values of A, B and C factors are given in Table 5. Fig. 1 shows the optimum cutting conditions of experiments to be conducted under the same conditions. The mean $\mathrm{S} / \mathrm{N}$ ratio of every level of the experiment is as shown in Table 5. 
International Journal of Recent advances in Mechanical Engineering (IJMECH) Vol.3, No.3, August 2014

Table $5 \mathrm{~S} / \mathrm{N}$ response table for RMS of vibration factor in axial direction

\begin{tabular}{cccc}
\hline Level & A & B & C \\
\hline 1 & -0.4612 & -6.8347 & -7.8741 \\
2 & -10.1149 & -8.6629 & -7.9542 \\
3 & -14.2979 & -9.3764 & -9.0456 \\
Delta & 13.8368 & 2.5417 & 1.1715 \\
\hline
\end{tabular}

The different values of $\mathrm{S} / \mathrm{N}$ ratio between maximum and minimum are (main effect) also presented in Table 5. The cutting speed and the depth of cut are two factors that have the highest difference between values, 13.8368 and 2.5417 respectively. As per the Taguchi prediction, the larger difference between the values of $\mathrm{S} / \mathrm{N}$ ratio will have a more significant effect on cutting tool vibration. Consequently, increasing the cutting speed will increase the cutting tool vibration significantly and also the depth of cut. The results of data analysis of $\mathrm{S} / \mathrm{N}$ ratio for vibration level of cutting tool in terms of RMS values, which are calculated by using Taguchi method, are shown in Table 4. Thus, it is seen in Fig. 1 and Table 5 that the value of first level of factor A, B and C i.e. cutting speed, depth of cut and feed rate are higher. Consequently, the optimum cutting conditions determined under the same conditions for the experiments to be conducted will be carbon steel as a cutting tool, $100 \mathrm{~m} / \mathrm{min}$ for the cutting speed, and $0.5 \mathrm{~mm}$ for the depth of cut and $0.1 \mathrm{~mm} / \mathrm{rev}$ for the feed rate.

\subsubsection{For tangential direction}

$\mathrm{S} / \mathrm{N}$ ratios of the vibration data acquired from the experimental results, which will be applied to define the optimal levels of each variable, were calculated according to Eq. (1). Fig. 2 shows the graphs of $\mathrm{S} / \mathrm{N}$ ratios that were calculated for tool vibration in tangential direction. The Taguchi design was conducted to obtain the value of RMS of vibration in tangential direction too. According to the Taguchi design the level values obtained from MINITAB 16 Program are given in Table 6. Accordingly, Fig. 2 and Table 6 shows that the first level of A factor (cutting speed), the first level of the B factor (depth of cut) and the first level of the $\mathrm{C}$ factor (feed rate) are higher. Therefore, optimum cutting conditions for the experiments to be conducted will be (1 111 ) carbon steel as a cutting tool, $100 \mathrm{~m} / \mathrm{min}$ for cutting speed, $0.5 \mathrm{~mm}$ for depth of cut and $0.1 \mathrm{~mm} / \mathrm{rev}$ for feed rate.

Table $6 \mathrm{~S} / \mathrm{N}$ response table for RMS of vibration factor in tangential direction

\begin{tabular}{cccc}
\hline Level & A & B & C \\
\hline 1 & -5.702 & -8.551 & -9.782 \\
2 & -12.419 & -11.739 & -11.121 \\
3 & -15.778 & -13.610 & -12.997 \\
Delta & 10.076 & 5.059 & 3.215 \\
\hline
\end{tabular}


Main Effects Plot for SN ratios

Data Means

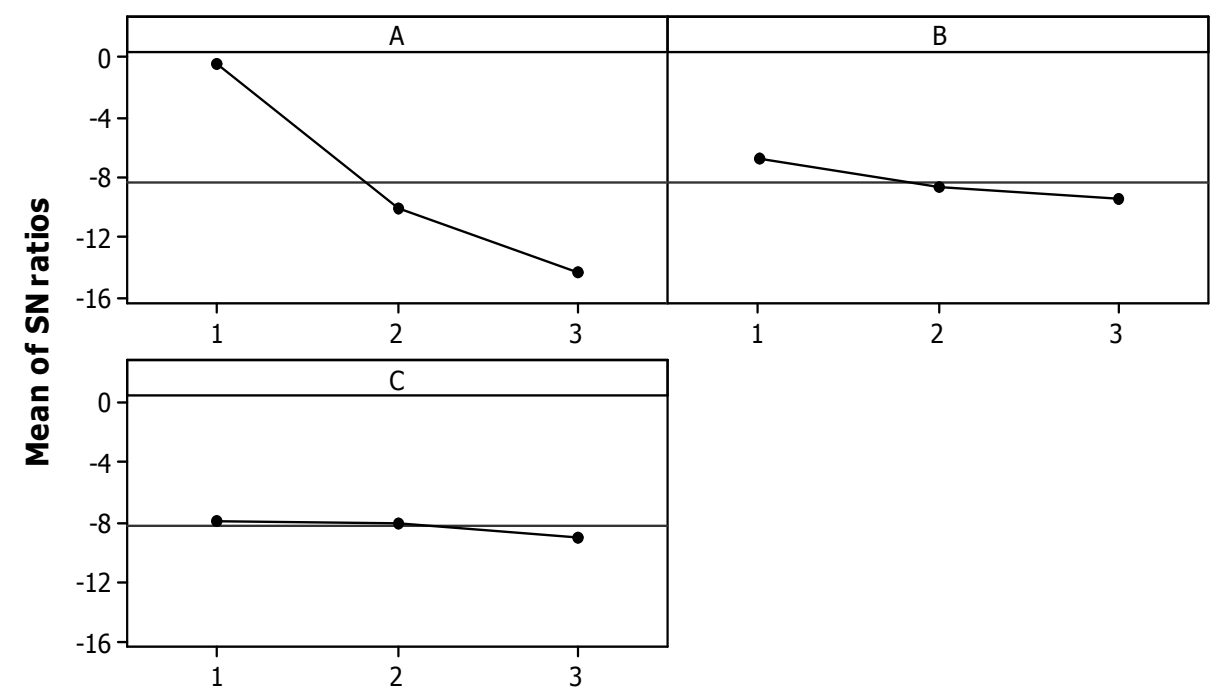

Fig. 1 Main effect plot for $\mathrm{S} / \mathrm{N}$ ratios of tool vibration in axial direction

Main Effects Plot for SN ratios

Data Means



Fig. 2 Main effect plot for $\mathrm{S} / \mathrm{N}$ ratios of tool vibration in tangential direction

\subsection{ANOVA and effect of the factors}

\subsubsection{For axial direction}

In this study, ANOVA was used to analyze the effects of cutting speed, feed rate and depth of cut on cutting tool vibration. In addition, multiple regression analysis was applied to derive the mathematical models of the control factors and their interactions. ANOVA is a statistical method used to find out the individual interactions of all control factors. In the analysis, the percentage 
distributions of each control factor were used to measure the corresponding effects on the quality characteristics. The performed experimental plan was evaluated at 95\% of confidence level. ANOVA values belonging to experimental results for the vibration level of cutting tool in term of RMS of vibration and S/N ratios are shown in Tables 7 and 8, respectively. The significance of control factors in ANOVA is determined by comparing the $\mathrm{F}$ value of each control factor and $\mathrm{F}$ 0.05 value from table.

Table 7 ANOVA for RMS of vibration factor in axial direction

\begin{tabular}{lllllll}
\hline Source & $\begin{array}{l}\text { Degree } \\
\text { freedom (DF) }\end{array}$ & $\begin{array}{l}\text { Sum of } \\
\text { squares } \\
(\mathrm{SS})\end{array}$ & $\begin{array}{l}\text { Mean of } \\
\text { squares } \\
(\mathrm{MS})\end{array}$ & $\begin{array}{l}\mathrm{F} \\
\text { Ratio }\end{array}$ & $\begin{array}{l}\text { P } \\
\text { Value }\end{array}$ & $\begin{array}{l}\text { PCR } \\
(\%)\end{array}$ \\
\hline $\mathrm{A}$ & 2 & 25.8244 & 12.9122 & 33.79 & 0.029 & 93.24 \\
$\mathrm{~B}$ & 2 & 1.0273 & 0.5136 & 1.34 & 0.427 & 3.71 \\
$\mathrm{C}$ & 2 & 0.0795 & 0.0397 & 0.10 & 0.906 & 0.28 \\
Error & 2 & 0.7644 & 0.3822 & & & 2.76 \\
Total & 8 & 27.6955 & & & & 100.00 \\
\hline
\end{tabular}

Table 8 ANOVA for $\mathrm{S} / \mathrm{N}$ ratios for RMS of vibration factor in axial direction

\begin{tabular}{|c|c|c|c|c|c|c|}
\hline Source & $\begin{array}{l}\text { Degree of } \\
\text { freedom (DF) }\end{array}$ & $\begin{array}{l}\text { Sum of } \\
\text { squares } \\
(\mathrm{SS})\end{array}$ & $\begin{array}{l}\text { Mean of } \\
\text { squares } \\
(\mathrm{MS})\end{array}$ & $\begin{array}{l}\text { F } \\
\text { Ratio }\end{array}$ & $\begin{array}{l}\mathrm{P} \\
\text { Value }\end{array}$ & $\begin{array}{l}\text { PCR } \\
(\%)\end{array}$ \\
\hline A & 2 & 302.148 & 151.074 & 194.06 & 0.005 & 95.43 \\
\hline B & 2 & 10.312 & 5.156 & 6.62 & 0.131 & 3.25 \\
\hline $\mathrm{C}$ & 2 & 2.570 & 1.285 & 1.65 & 0.377 & 0.81 \\
\hline Error & 2 & 1.557 & 0.778 & & & 0.491 \\
\hline Total & 8 & 316.587 & & & & 100.00 \\
\hline
\end{tabular}

The results of ANOVA and their $\mathrm{S} / \mathrm{N}$ ratios which were done to determine the significance level of variable on the RMS of vibration occurred during the machining of EN 24 steel in axial direction (Table 7 and 8). F ratios and their PCR were taken into consideration to determine the significance level of the variables. Table 7 and 8 both indicate that the most effective variable on the tool vibration is the cutting speed with $95.43 \%$ and $93.24 \%$ of PCR respectively. The other variables that have an effect on tool vibration are depth of cut with $3.25 \%$ and $3.71 \%$ and feed rate with $0.81 \%$ and $0.21 \%$ respectively.

\subsubsection{For tangential direction}

The results of ANOVA for RMS of vibration and their $\mathrm{S} / \mathrm{N}$ ratios which were executed to find the significance level of the variable on the tool vibration occurred during the machining of EN 24 steel in tangential direction is given in Table 9 and 10. Table 9 and 10 both indicates that the most effective variable on the cutting tool vibration is the cutting speed with $72.35 \%$ and $82.62 \%$ of PCR respectively. The other variables that have an effect on tool vibration are depth of cut with $17.98 \%$, and $14.21 \%$ and feed rate with $7.16 \%$ and $2.71 \%$ respectively. 
International Journal of Recent advances in Mechanical Engineering (IJMECH) Vol.3, No.3, August 2014

Table 9 ANOVA for RMS of vibration factor in tangential direction

\begin{tabular}{lllllll}
\hline Source & $\begin{array}{l}\text { Degree of } \\
\text { freedom (DF) }\end{array}$ & $\begin{array}{l}\text { Sum of } \\
\text { squares } \\
(\mathrm{SS})\end{array}$ & $\begin{array}{l}\text { Mean of } \\
\text { squares } \\
(\mathrm{MS})\end{array}$ & $\begin{array}{l}\mathrm{F} \\
\text { Ratio }\end{array}$ & $\begin{array}{l}\text { P } \\
\text { Value }\end{array}$ & $\begin{array}{l}\text { PCR } \\
(\%)\end{array}$ \\
\hline $\mathrm{A}$ & 2 & 24.5052 & 12.2526 & 188.95 & 0.005 & 82.62 \\
$\mathrm{~B}$ & 2 & 4.2168 & 2.1084 & 32.51 & 0.030 & 14.21 \\
$\mathrm{C}$ & 2 & 0.8056 & 0.4028 & 6.21 & 0.139 & 2.71 \\
Error & 2 & 0.1297 & 0.0648 & & & 0.43 \\
Total & 8 & 29.6573 & & & & \\
\hline
\end{tabular}

Table 10 ANOVA for S/N ratios for RMS of vibration factor in tangential direction

\begin{tabular}{lllllll}
\hline Source & $\begin{array}{l}\text { Degree } \\
\text { freedom (DF) }\end{array}$ & $\begin{array}{l}\text { Sum of } \\
\text { squares } \\
(\mathrm{SS})\end{array}$ & $\begin{array}{l}\text { Mean of } \\
\text { squares } \\
(\mathrm{MS})\end{array}$ & $\begin{array}{l}\mathrm{F} \\
\text { Ratio }\end{array}$ & $\begin{array}{l}\text { P } \\
\text { Value }\end{array}$ & $\begin{array}{l}\text { PCR } \\
(\%)\end{array}$ \\
\hline $\mathrm{A}$ & 2 & 157.936 & 78.968 & 28.98 & 0.033 & 72.35 \\
$\mathrm{~B}$ & 2 & 39.257 & 19.628 & 7.20 & 0.122 & 17.98 \\
$\mathrm{C}$ & 2 & 15.648 & 7.824 & 2.87 & 0.258 & 7.16 \\
Error & 2 & 5.449 & 2.725 & & & 2.49 \\
Total & 8 & 218.290 & & & & \\
\hline
\end{tabular}

\subsection{Regression Equations}

According to Huang and Chen [23], the correlations between the factors and the performance measures were modeled using quadratic regressions. The equations of RMS of vibration axial and tangential error were generated based on the control factors and their interactions. The predictive equations generated for cutting tool vibration in terms of RMS in axial $\left(\zeta_{\text {axial }}\right)$ and tangential ( $\left.\zeta_{\text {tangential }}\right)$ directions are given in Eqs. (2) and (3) respectively. The estimated regression coefficients for RMS of vibration in axial and tangential using data in uncoded units are shown in Tables 11 and 12.

$$
\begin{aligned}
& \zeta_{\text {axial1 }}=-2.01111+2.07333 \mathrm{~A}+0.41 \mathrm{~B}+0.111667 \mathrm{C} \\
& \zeta_{\text {tangential1 }}=-2.23111+2.02 \mathrm{~A}+0.838333 \mathrm{~B}+0.351667 \mathrm{C}
\end{aligned}
$$

The empirical equation (2) and (3) shows a better agreement, greater than $95 \%$ in the fit values. Hence, these equations can be used for calculating the amplitude of tool vibration in term of RMS from machining parameters. ANOVA was derived to check the null hypothesis for the regression presented in Tables 13 and 14. The result shows that the estimated model significant with a level of significance alpha equal to 0.05 .

R-squared $\left(R^{2}\right)$ amount was calculated to verify the goodness of fit. $R^{2}$ (coefficient of determination) values for the RMS of vibration in axial $\left(\zeta_{\text {axial }}\right)$ and tangential $\left(\zeta_{\text {tangential }}\right)$ directions were calculated as 0.970 and 0.993 respectively. On the other hand, the predictive equations which contain the control factors and their interactions for RMS of vibration in axial $\left(\zeta_{\text {axial }}\right)$ and tangential ( $\left.\zeta_{\text {tangential }}\right)$ directions are shown in Eqs. (4) and (5), respectively. 
International Journal of Recent advances in Mechanical Engineering (IJMECH) Vol.3, No.3, August 2014

$$
\begin{gathered}
\zeta_{\text {axial } 2}=-0.669683+0.871905 \mathrm{~A}-0.0557143 \mathrm{~B}+0.21381 \mathrm{C}+0.398571 \mathrm{~A} \times \mathrm{B}+ \\
0.171429 \mathrm{~A} \times \mathrm{C}-0.122857 \mathrm{~B} \times \mathrm{C}
\end{gathered}
$$

$\zeta_{\text {tangential2 }}=-2.16254+1.73143 \mathrm{~A}+1.23905 \mathrm{~B}+0.159524 \mathrm{C}-0.0585714 \mathrm{~A} \times \mathrm{B}+$

$$
0.178571 \mathrm{~A} \times \mathrm{C}-0.0971429 \mathrm{~B} \times \mathrm{C}
$$

In the interactive model, $R^{2}$ values of the equations were calculated as 0.991 and 0.997 , respectively. The coefficient of determination of RMS of vibration in axial direction became $99.1 \%$ in interactive factor model, while it was calculated as $97 \%$ in factor model. Similarly, the coefficient of determination of RMS of vibration in tangential direction became $99.7 \%$ in interactive factor model, while it was calculated as $99.3 \%$ in factor model. Thus, the interactive regression models for both RMS of vibration value in axial and tangential direction ( $\zeta_{\text {axial2 }}$ and $\zeta_{\text {tangential2) }}$ are suggested.

Table11 Coefficient for regression analysis, response RMS of vibration in axial direction

\begin{tabular}{lllll}
\hline Predictor & Coefficient Seq. & SE Coefficient & T & Prob. \\
& SS & & & \\
\hline Constant & -2.0111 & 0.5883 & -3.42 & 0.019 \\
A & 2.0733 & 0.1653 & 12.54 & 0.000 \\
B & 0.4100 & 0.1653 & 2.48 & 0.056 \\
C & 0.1117 & 0.1653 & 0.68 & 0.529 \\
\hline
\end{tabular}

Table 12 Coefficient for regression analysis, response RMS of vibration in tangential direction

\begin{tabular}{lllll}
\hline Predictor & Coefficient Seq. & SE Coefficient & T & Prob. \\
& SS & & & \\
\hline Constant & -2.2311 & 0.3020 & -7.39 & 0.001 \\
A & 2.02000 & 0.08486 & 23.80 & 0.000 \\
B & 0.83833 & 0.08486 & 9.88 & 0.000 \\
C & 0.35167 & 0.08486 & 4.14 & 0.009 \\
\hline
\end{tabular}

Table 13 ANOVA table for the fitted model RMS of vibration in axial direction

\begin{tabular}{lllllll}
\hline Source & DF & Seq SS & MS & F & P & Remarks \\
\hline Regression & 3 & 26.8757 & 8.9586 & 54.64 & 0.000 & Adequate \\
Residual Error & 5 & 0.8198 & 0.1640 & & & \\
Total & 8 & 27.6955 & & & & \\
$\mathrm{R}^{2}$ & & & & & & $97.0 \%$ \\
$\mathrm{R}^{2}$ adjusted & & & & & & $95.3 \%$ \\
\hline
\end{tabular}


International Journal of Recent advances in Mechanical Engineering (IJMECH) Vol.3, No.3, August 2014

Table 14 ANOVA table for the fitted model RMS of vibration in tangential direction

\begin{tabular}{lllllll}
\hline Source & DF & Seq SS & MS & F & P & Remarks \\
\hline Regression & 3 & 29.4412 & 9.8137 & 227.11 & 0.000 & Adequate \\
Residual Error & 5 & 0.2161 & 0.0432 & & & \\
Total & 8 & 29.6573 & & & & \\
$\mathrm{R}^{2}$ & & & & & & $99.3 \%$ \\
$\mathrm{R}^{2}$ adjusted & & & & & $98.8 \%$ \\
\hline
\end{tabular}

\subsection{Surface plots}

A graphical analysis of the observed values was realized using Minitab 16. Fig. 3a-3d shows the estimated response surface plots for cutting tool vibration level in term of RMS versus the cutting parameters i.e. cutting speed, feed rate, and depth of cut. Fig. 3a shows the estimated vibration level of cutting tool for the corresponding cutting speed and depth of cut. Depth of cut has the most effect on the vibration level of cutting tool and its variation is very high when compared to other parameters. This figure also displays that the vibration increases as the cutting speed increases. The lower level of vibration was achieved at the lowest depth of cut and lowest cutting speed combination as expected. Fig. 3b shows the estimated response to the corresponding cutting speed and feed rate. Cutting speed has a most significant effect on the cutting tool vibration. As has been previously pointed out, cutting speed around $100 \mathrm{rpm}$ gives the lowest level of vibration. RMS value is also increased as the feed rate increases. The response for the consequent cutting speed and depth of cut in tangential direction as shown in fig. 3c. It is established that cutting speed has the highest impact on cutting tool vibration. The relation between cutting speed and feed rate with respect to RMS parameter is presented in Fig. $3 \mathrm{~d}$ shows the estimated response of vibration level of cutting tool for the corresponding feed rate and cutting speed. The vibration level reduces when the speed decreases from 200 to $100 \mathrm{rpm}$.

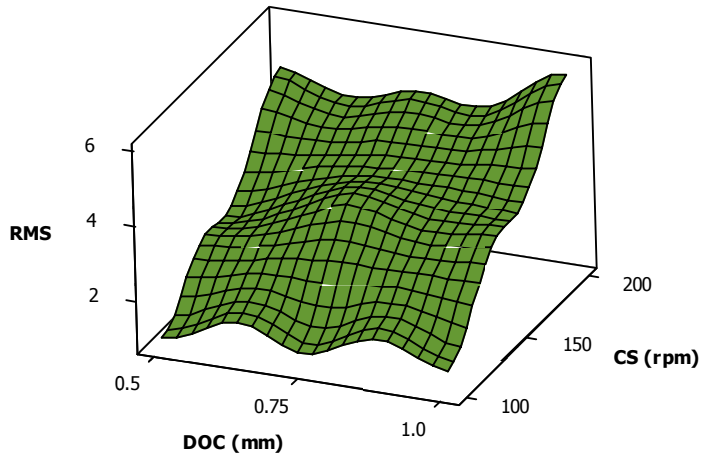

(a)



(b) 


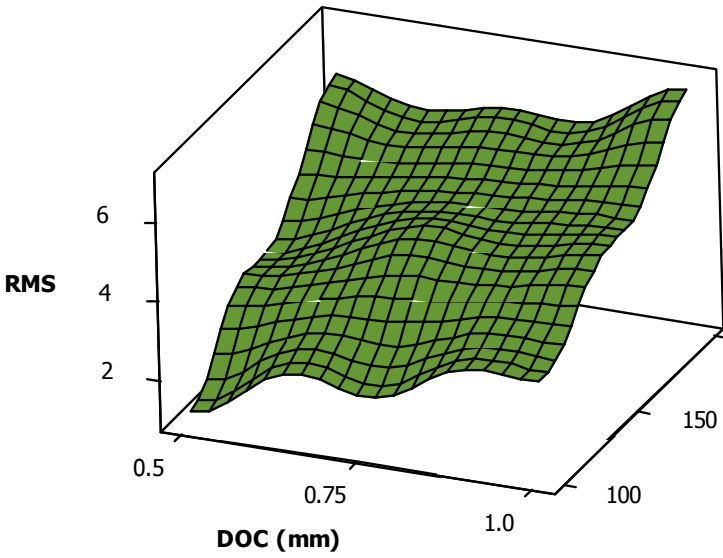

(c)

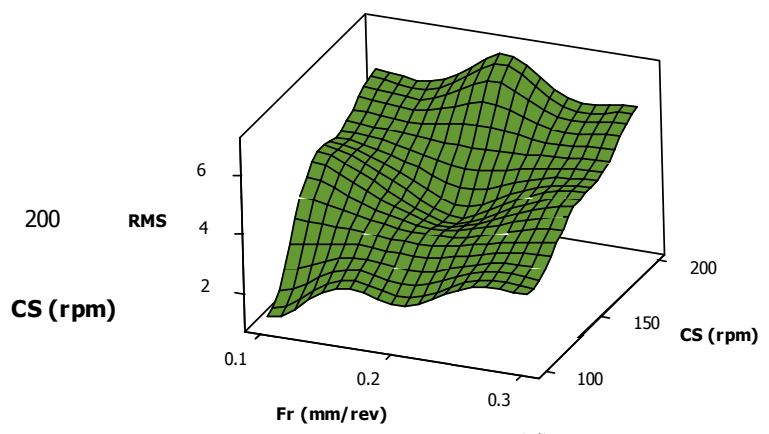

(d)

Fig. 3 (a) - (d) Response surface plots of RMS of vibration in axial and tangential direction according to change of cutting speed, feed rate and depth of cut.

\subsection{Confirmation Experiments}

The final step is the confirmation of experiments conducted for examining the quality characteristics. The model employed in the confirmation tests is defined by the total effect generated by the control factors. The factors are alike to the sum of each individual effect. The optimum levels are evaluated. The optimal values of RMS of vibration were obtained by taking into account the influential factors within the evaluated optimum combination in both the direction i.e. axial and tangential. Therefore, the predicted optimum cutting tool vibration level in term of RMS in both axial and tangential direction (Eq. (6 and 7)) were calculated by considering individual effects of the factors $A_{1}, B_{1}$ and $C_{1}$, and their levels. The predicted RMS values of vibration in both axial and tangential directions were determined as 0.525 and 1.002 respectively.

$$
\begin{aligned}
& \eta_{\text {axialp }}=\overline{\eta_{a}}+\left(\overline{A_{0}}-\overline{\eta_{a}}\right)+\left(\overline{B_{0}}-\overline{\eta_{a}}\right)+\left(\overline{C_{0}}-\overline{\eta_{a}}\right) \\
& \eta_{\text {tangentialp }}=\overline{\eta_{t}}+\left(\overline{A_{0}}-\overline{\eta_{t}}\right)+\left(\overline{B_{0}}-\overline{\eta_{t}}\right)+\left(\overline{C_{0}}-\overline{\eta_{t}}\right)
\end{aligned}
$$

In these equations, $\eta_{\text {axialp }}$ and $\eta_{\text {tangentialp }}$ are the predicted value of RMS of vibration in axial and tangential direction, $\overline{\eta_{a}}$ and $\overline{\eta_{t}}$ are the mean of RMS of vibration in both the axial and tangential direction, $\overline{A_{0}}$ is the mean of RMS of vibration when the variable $\mathrm{A}$ is at optimum level, $\overline{B_{0}}$ is the mean of RMS of vibration when the variable B is at optimum level, $\overline{C_{0}}$ is the mean of RMS of vibration when the variable $\mathrm{C}$ is at optimum level. Fig. 4 shows the comparison between the predicted values of RMS of vibration from the quadratic model of response equation and the measured values via experimentally. The predicted values of the RMS of vibration parameters for axial direction is shown fig. $4 \mathrm{a}$ and fig. $4 \mathrm{~b}$ are very close to those recorded experimentally in tangential direction. 


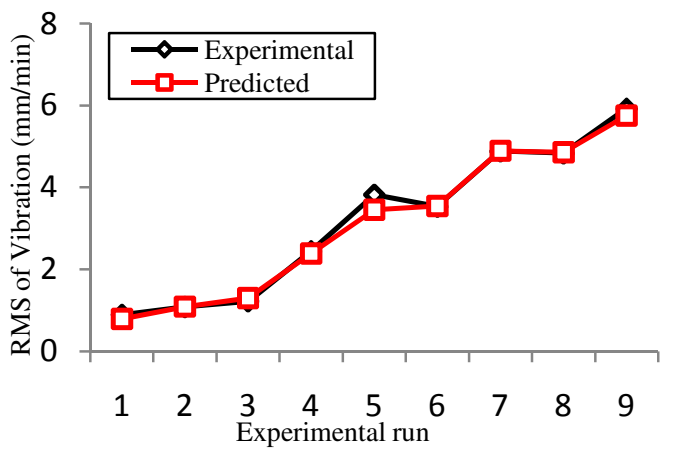

(a)



(b)

Fig. 4 (a) and (b) Comparison between measured and predicted value of RMS of vibration in axial and tangential direction.

Table 15 Comparison between experiment result and predicted values

\begin{tabular}{|c|c|c|c|c|c|c|}
\hline \multirow{2}{*}{$\begin{array}{l}\text { Directions } \\
\text { Axial }\end{array}$} & \multicolumn{2}{|c|}{ Actual values } & \multicolumn{2}{|c|}{ Predicted Value } & \multicolumn{2}{|l|}{ Difference } \\
\hline & $\mathrm{RMS}_{\mathrm{act}}$ & $\mathrm{S} / \mathrm{N}$ ratio & $\mathrm{RMS}_{\mathrm{pred}}$ & $\mathrm{S} / \mathrm{N}$ ratio pred & $\mathrm{RMS}_{\mathrm{act}}-\mathrm{RMS}_{\mathrm{pred}}$ & $\mathrm{S} / \mathrm{N}$ ratio ${ }_{a c t}-\mathrm{S} / \mathrm{N}$ ratio pred \\
\hline & 0.89 & 1.01 & 0.525 & 1.42 & 0.365 & -0.41 \\
\hline Tangential & $\mathrm{RMS}_{\mathrm{act}}$ & $\mathrm{S} / \mathrm{N}$ ratio ${ }_{\text {act }}$ & $\mathrm{RMS}_{\mathrm{pred}}$ & $\mathrm{S} / \mathrm{N}$ ratio pred & $\mathrm{RMS}_{\mathrm{act}}-\mathrm{RMS}_{\mathrm{pred}}$ & $\mathrm{S} / \mathrm{N}$ ratio ${ }_{a c t}-\mathrm{S} / \mathrm{N}$ ratio pred \\
\hline & 1.04 & -0.34 & 1.02 & -1.43 & 0.02 & 1.09 \\
\hline
\end{tabular}

Table 15 gives a comparison of the results of the confirmation experiment which were conducted according to the optimum levels of the variables and the values calculated using Eqs. (10) and (11). It can be seen from Table 15 that the difference between the predicted value of RMS of vibration (0.365) calculated for axial direction. Similarly, the difference between the predicted value of RMS of vibration results (0.02) calculated for tangential direction.

\section{Conclusions}

At the end of this research work, the following conclusions are drawn:

1) Based on the signal to noise $(\mathrm{S} / \mathrm{N})$ ratio using smaller is the better approach, we can conclude that the best optimal cutting condition is $A_{1} B_{1} C_{1}$ i.e. cutting speed is $100 \mathrm{rpm}$, depth of cut is $0.5 \mathrm{~mm}$ and feed rate is $0.1 \mathrm{~mm} / \mathrm{rev}$.

2) The smallest RMS of vibration occurred during machining of EN 24 steel with axial and tangential directions are obtained at 0.89 and 1.04 with carbon steel cutting tool, respectively. Therefore, it can say that the vibration level of cutting tool with axial direction is less as compared to tangential direction.

3) Analysis of variance (ANOVA) demonstrates that the cutting speed have the highest influence on the evolution of vibration level of cutting tool. For the arithmetic average 
International Journal of Recent advances in Mechanical Engineering (IJMECH) Vol.3, No.3, August 2014

vibration in term of RMS the influences are 93.24\%, $82.62 \%$ for axial and tangential direction, respectively. Besides the influence of depth of cut is $14.21 \%$ for tangential direction. Nevertheless, the feed rate has no influence on the vibration of cutting tool in both the directions.

4) Predicted values of RMS of vibration for both axial and tangential direction using regression analysis were very close to the experimental values which suggest that the regression model also holds good for tool vibration estimation of this newly developed cutting tool.

\section{ACKNOWLEDGEMENT}

The authors would like to express their deep gratitude to the Department of Mechanical engineering of Malaviya National Institute of Technology, Jaipur, India for providing the laboratory facilities and financial support.

\section{REFERENCES}

[1] Al-Habaibeh A. and Gindy N., A new approach for systematic design of condition monitoring systems for milling operation. Journal of Material Processing Technology, (2000); 107: 243-251.

[2] Dimla D.E., Sensors signals for tool-wear monitoring in metal cutting operations - A Review of methods. International Journal of Machine tools and Manufacture, (2000); 40: 1073-1098.

[3] Frankowiak M., Grosvenor R. and Prickett P., A review of the evolution of microcontroller-based machine and process monitoring. International Journal of Machine Tools \& Manufacturing, (2005); 45: 578-582.

[4] Jemielniak K. Commercial tool condition monitoring systems. International Journal of Advanced Manufacturing Technology, (1999), 15 (4): 711-721.

[5] Xiaoli Li. A brief review: acoustic emission method for tool wears monitoring during turning. International Journal of Machine tools and Manufacture, (2002); 42:157-165.

[6] Ghasempoor A, Jeswiet J, Moore TN, Real time implementation of on line tool condition monitoring in turning. Int j machine tools manufacturing (1999) 39:1883-1902

[7] Byrne G, Dornfeld D, Insaki I, Ketteler G, König W, Teti R Tool condition monitoring (TCM) - The status of research and industrial application. Annals of CIRP (1995) 44(2):541-567

[8] Aminollah Mohammadi, Alireza Fadaei Tehrani, Ehsan Emanian, Davoud Karimi, statistical analysis of wire electrical discharge turning on material removal rate, Journal of Materials Processing Technology 205 (2008) 283-289.

[9] Ting-Cheng Chang, Feng-Che Tsai, Jiuan-Hung Ke, Data mining and Taguchi method combination applied to the selection of discharge factors and the best interactive factor combination under multiple quality properties, Int J Adv Manuf Technol (2006) 31: 164-174.

[10] S. S. Mahapatra, Amar Patnaik, Optimization of wire electrical discharge machining (WEDM) process parameters using Taguchi method, Int J Adv Manufacturing Technology (2007) 34:911-925.

[11] Aminollah Mohammadi, Alireza Fadaei Tehrani, Ehsan Emanian, Davoud Karimi, A new approach to surface roughness and roundnessimprovement in wire electrical discharge turning based on statistical analyses, Int J Adv Manufacturing Technology (2008) 39:64-73.

[12] M.S. Phadke, Quality Engineering Using Robust Design, Prentice-Hall, Englewood Cliffs, NJ, (1989).

[13] Ranjit, K.R. A primer on the Taguchi method, competitive manufacturing series, Van Nostrand Reinhold, New York (1999)

[14] G. Taguchi, S. Chowdhury, Y. Wu, Taguchi's Quality Engineering Handbook, John Wiley \& Sons Inc., New Jersey, (2005).

[15] T.R. Lin, Optimization technique for face milling stainless steel with multiple performance characteristics, Int. J. Adv. Manuf. Technol. 19(2002) 330-335. 
[16] A. Hascalık, U. Caydas_, Optimization of turning parameters for surface roughness, and tool life based on the Taguchi method, Int. J.Adv. Manuf. Technol. 38 (2008) 896-903.

[17] M. S_anyılmaz, Design Of Experiment And an Application for Taguchi Method in Quality Improvement Activity, M.S. Thesis, Dumlupınar University, Turkey, (2006).

[18] E. Aslan, N. Camus_cu, B. Bingoren, Design optimization of cutting parameters when turning hardened AISI 4140(63 HRC) with Al2O3 + TiCN mixed ceramic tool, Mater. Des. 28 (2007) 16181622.

[19] J.A. Ghani, I.A. Choudhury, H.H. Hassan, Application of Taguchi method in the optimization of end milling operations, J. Mater. Process. Technol. 145 (2004) 84-92.

[20] S.H. Park, Robust Design and Analysis for Quality Engineering, Chapman and Hall, London, U.K, 1996.

[21] H.S. Kim, A combined FEA and design of experiments approach for the design and analysis of warm forming of aluminum sheet alloys, Int. J. Adv. Manuf. Technol. 51 (1-4) (2010) 1-14.

[22] S. Neseli, S. Yaldız, E. Turkes, Optimization of tool geometry parameters for turning operations based on the response surface methodology, Measurement 44 (3) (2011) 580-587.

[23] L. Huang, J.C. Chen, A multiple regression model to predict in process surface roughness in turning operation via accelerometer, Journal of Industrial Technology 17 (2) (2001) 1-8.

\section{Authors}

Amit Aherwar is currently pursuing his $\mathrm{PhD}$ in Mechanical Engineering from Malaviya National Institute of Technology, Jaipur. He received his bachelor's degree in Mechanical Engineering and master's degree in Production Engineering from the Rajiv Gandhi Technical University, Bhopal in 2006 and 2010, respectively. His research interests are condition monitoring, machine fault signature analysis, Vibration analysis, Tribology and

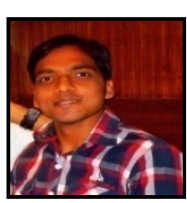
Lubricant monitoring analysis.

Deepak Unune is currently pursuing his Ph.D. from Malaviya National Institute of Technology, Jaipur. He received his bachelor's and master's degree in Mechanical Engineering from Shivaji University, Kolhapur in 2007 and 2011respectively. His research interests are non-conventional machining processes, hybrid machining processes.



Bhargav Pathri is currently pursuing his $\mathrm{PhD}$ in Mechanical Engineering from Malaviya National Institute of Technology, Jaipur. He received his bachelor's degree in Mechanical Engineering from SREC, Warangal in 2008and masters in Automotive Engineering from Coventry University (UK) in 2010. His research interests are Advance Manufacturing Processes, Rapid Prototyping and CAD/CAM.

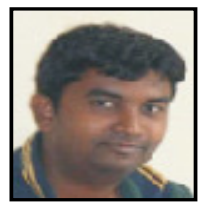

Jai Kishan is currently pursuing his $\mathrm{PhD}$ in Mechanical Engineering from Malaviya National Institute of Technology, Jaipur. He received his BE degree in Mechanical Engineering from MDU Rohtak in 2010 and M.Tech from S. V. National Institute of Technology, Surat in 2012. His research interests are Advance Machining Process, CAPP

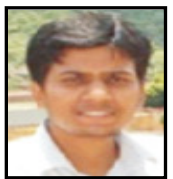
and Expert System. 